\title{
Revisão do gênero Eriphosoma (Coleoptera, Cerambycidae) ${ }^{1}$
}

\author{
Dilma Solange Napp ${ }^{2,4} \&$ Miguel A. Monné $e^{3,4}$
}

1. Contribuição $\mathrm{n}^{\mathrm{o}} 1610$ do Departamento de Zoologia da Universidade Federal do Paraná.

2. Departamento de Zoologia, Universidade Federal do Paraná, Caixa Postal 19020, 81531-980 Curitiba, PR, Brasil. (napp@ufpr.br)

3. Museu Nacional, Universidade Federal do Rio de Janeiro, Quinta da Boa Vista, São Cristóvão, 20940-040 Rio de Janeiro, RJ, Brasil.

(monne@uol.com.br)

4. Pesquisador do CNPq.

ABSTRACT. Revision of the genus Eriphosoma (Coleoptera, Cerambycidae). Eriphosoma Melzer, 1922 is redefined including five species: E. bipartitum (Buquet, 1844) (type species), E. barbiellinii Melzer, 1922, E. jacobi Fuchs, 1961, and two new species described from Brazil: E. marcela sp. nov., from Espírito Santo, and E. mermudes sp. nov., from Bahia and Minas Gerais. New combination proposed: Erythrochiton sellatum (Buquet, 1844). A key to the species of Eriphosoma is provided.

KEYWORDS. Cerambycinae, Eriphosoma, Heteropsini, Neotropical, revision.

RESUMO. Eriphosoma Melzer, 1922 é redefinido incluindo cinco espécies: E. bipartitum (Buquet, 1844) (espécie-tipo), E. barbiellinii Melzer, 1922, E. jacobi Fuchs, 1961 e duas espécies novas descritas do Brasil: E. marcela sp. nov. (Espírito Santo) e E. mermudes sp. nov. (Bahia e Minas Gerais). Nova combinação proposta: Erytrochiton sellatum (Buquet, 1844). Chave para as espécies de Eriphosoma é fornecida.

PALAVRAS-CHAVE. Cerambycinae, Eriphosoma, Heteropsini, Neotropical, revisão.

Eriphosoma Melzer, 1922 foi proposto para incluir três espécies: Eriphus bipartitus Buquet, 1844, Eriphus sellatus Buquet, 1844 e Eriphosoma barbiellinii Melzer, 1922 (Melzer, 1922), todas descritas do Brasil. Posteriormente, Fuchs (1961) acrescentou E. jacobi, descrita do Paraguai e Brasil.

Propõem-se duas novas espécies procedentes do Brasil: Eriphosoma marcela sp. nov. e E. mermudes sp. nov., e a transferência de Eriphosoma sellatum para o gênero Erythrochiton Zajciw, 1957.

As siglas citadas no texto correspondem a: Coleção Herbert Schmidt, Viena (CHSV), Departamento de Zoologia, Universidade Federal do Paraná, Curitiba (DZUP), Muséum National d'Histoire Naturelle, Paris (MNHN), Museu Nacional, Universidade Federal do Rio de Janeiro, Rio de Janeiro (MNRJ) e Museu de Zoologia, Universidade de São Paulo, São Paulo (MZSP). Considerando a recente publicação de um catálogo (MonNé, 2005), as referências citadas sob cada táxon restringem-se à descrição original e ao catálogo de Monné (2005).

\section{Eriphosoma Melzer, 1922}

Eriphosoma Melzer, 1922:10; Monné, 2005:289.

Espécie-tipo: Eriphus bipartitus Buquet, 1844, por designação original.

Cabeça opaca, fina- e densamente reticulada, pilosidade inconspícua. Fronte declive, curta, transversa e aplanada. Sutura fronto-clipeal indistinta. Tubérculos anteníferos arredondados e não-projetados. Genas com cerca de um terço da largura do lobo ocular inferior. Olhos finamente facetados, pouco chanfrados; lobos inferiores bem desenvolvidos, proeminentes, ocupam toda a região lateral da cabeça e avançam um pouco sobre a face ventral; faixa de ligação entre os lobos mais larga que um lobo superior; lobos superiores curtos, quase tão distantes entre si quanto o comprimento do escapo. Mandíbulas delgadas, arredondadas na face externa, aguçadas no ápice, grosseiramente pontuado-rugosas, brilhantes. Artículos apicais dos palpos maxilares e labiais fortemente expandidos para o ápice, pouco mais longos que a soma dos dois precedentes, que são curtos e subiguais. Submento pontuado-rugoso, com pilosidade esparsa.

Antenas filiformes, com 11 artículos, ultrapassam o ápice elitral em dois a três artículos nos machos; nas fêmeas, pouco mais curtas que o corpo ou ultrapassam o ápice elitral em um artículo. Antenômeros I-V(VI) com cerdas moderadamente longas na face inferior, mais adensadas nos III-IV. Escapo cilíndrico; antenômero III o mais longo, cerca de duas vezes o comprimento do escapo e um terço mais longo que o V; XI mais curto que o III, não-apendiculado; VI a X um pouco expandidos no ápice externo.

Protórax tão a pouco mais largo que longo, regularmente arredondado nos lados, a maior largura no meio. Pronoto um pouco convexo, sem gibosidades. Pronoto e lados do protórax opacos, fina- e densamente reticulados, pilosidade pouco aparente. Processo prosternal muito estreito entre as procoxas, discretamente expandido no ápice. Cavidades coxais anteriores fechadas nos lados e abertas atrás. Processo mesosternal aplanado, tão largo quanto uma mesocoxa, com lados paralelos e margem apical com entalhe mediano para encaixe da projeção anterior do metasterno. Cavidades coxais médias fechadas. Pro- e mesocoxas arredondadas, 
não-projetadas. Mesosterno, metasterno e urosternitos fina- e densamente corrugados, com pubescência esbranquiçada curta, adensada e cerdas alongadas esparsas. Ultimo urosternito transverso, com os lados um pouco convergentes para o ápice, que é truncado nos machos e arredondado nas fêmeas.

Escutelo pequeno, triangular. Élitros estreitos, aplanados no dorso e alongados, comprimento cerca de 3,0 a 3,5 vezes a largura umeral. Superfície opaca com pontos grossos nos dois terços basais, mais finos, densos e algo biselados no terço apical. Úmeros um pouco projetados para frente. Ápices entalhados no lado externo e obliquamente truncados junto à sutura.

Pernas longas e delgadas. Fêmures lineares, sem carena apical, as abas apicais angulosas e subiguais. Mesofêmures muito grossa-, densa- e fortemente alveolados. Metafêmures mais delgados que os mesofêmures, atingem ou ultrapassam o ápice elitral pela ponta dos fêmures nos machos; nas fêmeas, não atingem ou apenas ultrapassam o ápice elitral. Tíbias cilíndricas, um pouco deprimidas, carenadas nas duas faces, com pontos grossos e cerdas moderadamente densas na face inferior. Esporões tibiais curtos, o interno mais longo. Metatarsômero I mais longo que os II-V somados.

Discussão. Eriphosoma é semelhante a Erythropterus Melzer, 1934, diferindo por: (1) antenômeros III-V sem sulco; (2) antenas das fêmeas, pelo menos, tão longas quanto o corpo; (3) fórmula antenal: antenômero III com o dobro do comprimento do escapo, o IV mais longo que o escapo e pouco mais curto que o V; (4) protórax regularmente arredondado nos lados, com a maior largura no meio; (5) fêmures lineares, sem carena apical; (6) ápices elitrais com entalhe no lado externo, onde são bi-denteados, além da projeção no ângulo sutural; (7) artículos apicais dos palpos maxilares e labiais fortemente expandidos para o ápice. Em Erythropterus, os antenômeros III-V são sulcados e carenados; o III é cerca de um terço mais longo que o escapo, o IV tão longo quanto o escapo e evidentemente mais curto que o $\mathrm{V}$ e as antenas das fêmeas são mais curtas que o corpo; o protórax é alargado para trás com a maior largura atrás do meio, os fêmures são clavados e carenados na região apical, os ápices elitrais são obliquamente truncados e os artículos apicais dos palpos são estreitados na base e pouco expandidos para o ápice (NAPP \& MonNÉ, 2005).

Chave para as espécies de Eriphosoma

1. Protórax alaranjado 2 Protórax preto

2(1). Antenômeros III a V com fina carena látero-dorsal, os III-IV com espinho apical interno curto. Metasterno, metepisternos e urosternitos com pontos moderadamente grossos e bastante rasos, uniformemente distribuídos em toda a superfície. Mesofêmures com pontos alongados e muito grossos em toda a superfície. Machos com áreas de pontuação sexual na metade anterior dos lados do pronoto e do protórax. (Élitros pretos; pronoto sem máculas pretas látero-basais) (Fig. 6). Brasil (Espírito Santo) .... E. marcela sp. nov.

Antenômeros III a V sem carenas, os IIII-IV inermes. Metasterno, metepisternos e urosternitos sem pontos grossos. Mesofêmures com pontos arredondados e conspicuamente mais finos no quarto apical. Machos sem pontuação sexual. (Élitros pretos ou bicolores: alaranjados na metade ou nos $2 / 3$ anteriores, pretos no restante; pronoto usualmente com mácula preta a cada lado da base) (Figs. 1, 2). Brasil (Minas Gerais, Rio de Janeiro a Santa Catarina), Paraguai, Argentina

E. bipartitum (Buquet, 1844)

3(1). Élitros inteiramente pretos, com pilosidade esbranquiçada e grande área aveludada preta de aspecto triangular que abrange toda a região basal e se estende aos lados da sutura até o meio dos élitros; região basal com pontos grossos e adensados, não-alinhados (Figs. 3, 5). Brasil (Bahia, Minas Gerais)

E. mermudes sp. nov.

Élitros bicolores, com pilosidade amarelada e sem região aveludada; região basal com pontos alinhados e tão ou mais distantes entre si quanto o diâmetro de um ponto ................... 4

4(3). Élitros vermelhos com o quinto apical preto (Figs. 7, 8). Brasil (Santa Catarina), Paraguai E. jacobi Fuchs, 1961

Élitros amarelos com faixa sutural e o terço apical, pretos (Fig. 4). Brasil (Rio de Janeiro, São Paulo) .................. E. barbiellinii Melzer, 1922

\section{Eriphosoma bipartitum (Buquet, 1844)} (Figs. 1, 2)

Eriphus bipartitus BuQuet in GuéRIN-Méneville, 1844:226. Eriphosoma bipartitum; Melzer, 1922:11; Monné, 2005:289 (cat.). Eriphosoma bipartitum var. axillaris Melzer, 1922:11; Monné, 1994:31 (sin.); Monné, 2005:289 (in syn.).

Macho. Cabeça, antenas, escutelo, pernas, mesosterno, metasterno e urosternitos pretos. Protórax alaranjado com uma mácula preta a cada lado da base. Élitros (Figs. 1,2) pretos ou bicolores: amarelos na metade ou nos dois terços basais, pretos no restante.

Clípeo grossa- e densamente pontuado, com área centro-basal elevada, microesculturada, sem pontos. Genas pouco mais longas que um terço da largura do lobo ocular inferior, densamente pontuadas, discretamente aguçadas no ápice, pilosidade inaparente. Artículos apicais dos palpos maxilares e labiais fortemente dilatados para o ápice.

Antenas ultrapassam o ápice elitral em 2,5-3,0 artículos. Escapo opaco, grossa- e densamente pontuado, com pilosidade esparsa. Antenômeros III-V nãocarenados e desarmados; fina- e densamente pontuados, com pilosidade curta e deitada e pêlos pouco alongados 
e esparsos na face inferior; VI-XI finamente pubescentes. Antenômeros V-VIII e o XI com comprimentos subiguais, cerca de um quarto mais curtos que o III.

Protórax tão longo quanto largo. Pronoto e lados do protórax com pontuação reticulada rasa, subglabros, com raras cerdas longas e eretas e sem áreas de pontuação sexual. Prosterno brilhante, com rugas e pontos pouco marcados e pubescência esbranquiçada pouco aparente. Mesosterno, metasterno e urosternitos fina- e densamente corrugados, com pubescência esbranquiçada curta mais adensada nas regiões laterais, e cerdas esbranquiçadas, longas e esparsas.

Escutelo opaco, subglabro, impontuado ou com pontos esparsos. Élitros de lados subparalelos. Na região de tegumento amarelado, com pontos grossos, irregularmente alinhados, tão ou mais distantes entre si quanto o diâmetro de um ponto; na margem anterior de cada ponto, uma cerda alaranjada, subereta; a região com tegumento preto fortemente microesculturada com pontos menores, mais densos, não-alinhados e um pouco ásperos, com cerdas amareladas mais aparentes. Ápices com espinho externo do entalhe curto, o ângulo sutural projetado.

Mesofêmures com cerdas abundantes e pontos grossos e arredondados, evidentemente mais finos no quarto apical; metafêmures com pontos rasos, menores e menos densos e cerdas mais esparsas.

Fêmea (Fig. 2). Antenas ultrapassam o ápice elitral em um artículo. Metafêmures mais fortemente pontuados, atingem ou apenas ultrapassam o ápice elitral. Protórax tão a pouco mais largo que longo.

Dimensões, em $\mathrm{mm}$, ठ/ఢ respectivamente. Comprimento total $8,6-8,2 / 9,5-8,5$; comprimento do protórax 1,8-1,7/1,8-1,7; largura do protórax 1,8-1,7/2,0-1,7; comprimento do élitro 6,3-6,2/7,2-6,3; largura umeral 2,12,0/2,3-2,1.

Variabilidade. Nos exemplares provenientes da Argentina e do Paraguai, os élitros são inteiramente pretos (Fig. 2) e, em alguns espécimens, as máculas pretas nos lados da base do pronoto são pouco distintas. Essa variabilidade já havia sido observada por ZAJCIW (1962:451) que menciona, ainda, exemplares “....com élitros negros ornados de placas oblongas, vermelhoalaranjados nos úmeros e que devem corresponder à var. axillaris Melzer."

Material-tipo. A espécie foi descrita com base em único exemplar procedente "du Brésil” (BUQueT, 1844:226) e depositado no MNHN. O holótipo, provavelmente macho, estudado através de diapositivo, tem quase toda a metade apical dos élitros negra.

Discussão. Entre as cinco espécies aqui reconhecidas em Eriphosoma, apenas E. bipartitum e E. marcela sp. nov. (Fig. 6) têm o protórax inteiramente alaranjado. As duas espécies se diferenciam pelos caracteres mencionados na chave. Pelos élitros bicolores, E. bipartitum assemelha-se a E. barbiellinii, da qual difere pelo colorido alaranjado do protórax com reticulação muito superficial, antenas desarmadas, élitros sem faixa preta nos lados da sutura e ausência de pontuação sexual nos machos. Em E. barbiellinii, o protórax é inteiramente preto, com pontuação reticulada bem marcada, os antenômeros III-IV têm espinho apical interno curto, os élitros apresentam uma faixa preta nos lados da sutura e os machos, áreas de pontuação sexual nos lados do pronoto e do protórax.

Distribuição. MonNé (2005) registra E. bipartitum para o Brasil (Minas Gerais a Santa Catarina) e Paraguai. A distribuição da espécie é aqui ampliada para a Argentina.

Material examinado. BRASIL, Rio de Janeiro: Rio de Janeiro (Corcovado), क, 22.X.1958, Alvarenga \& Seabra col. (DZUP); 2 \&, IX.1961, Alvarenga \& Seabra col. (MNRJ, DZUP); \&, 7.XI.1962, Alvarenga \& Seabra col. (MNRJ); đ', 26.XI.1962, Alvarenga \& Seabra col. (MNRJ); đ, 6.X.1967, Moure \& Seabra col. (DZUP). PARAGUAI. Itapúa: †, XII.1956 (MNRJ). ARGENTINA, Misiones: Loreto, 3 đ̊, X.1955; đ̋, 2 \&, XII.1955; oै, X.1959 (MNRJ).

\section{Eriphosoma barbiellinii Melzer, 1922}

(Fig. 4)

Eriphosoma barbiellinii Melzer, 1922:11; MonnÉ, 2005:289.

Macho. Protórax preto. Élitros (Fig. 4) bicolores: amarelos com o terço apical e faixa sutural, pretos.

Artículos apicais dos palpos maxilares e labiais menos expandidos para os ápices. Antenas ultrapassam o ápice elitral em dois artículos; antenômeros III-IV com espinho curto no ápice interno e espículo no externo. Antenômeros $\mathrm{V}-\mathrm{X}$ pouco e gradualmente decrescentes, o XI mais curto que o $\mathrm{V}$ e cerca de um terço mais curto que o III.

Pronoto e lados do protórax forte- e densamente reticulados. Na metade anterior, a cada lado do pronoto e do protórax, com áreas de pontuação sexual, ovaladas e deprimidas, com pontos grossos, irregulares e contíguos e microescultura fraca, deixando o tegumento dessas áreas mais brilhante que o restante da superfície. Prosterno pontuado-rugoso, a escultura bem evidente.

Metafêmures com pontuação bem evidente: fina e densa na metade basal, mais esparsa e com aspecto áspero na apical.

Fêmea. Antenas desde pouco mais curtas até pouco mais longas que o corpo. Lados do pronoto e protórax sem áreas de pontuação sexual.

Dimensões, em $\mathrm{mm}, \sigma^{2} / \$$ respectivamente. Comprimento total 10,6-7,6/10,7-9,7; comprimento do protórax 2,2-1,5/2,0-1,8; largura do protórax 2,0-1,5/2,21,8 ; comprimento do élitro 7,9-5,8/8,1-7,3; largura umeral $2,5-1,8 / 2,7-2,2$.

Variabilidade. O colorido preto dos élitros, na metade apical e nos lados da sutura, pode variar em extensão, chegando a ser predominante em alguns exemplares, o que está de acordo com a descrição original: "...elytris singulus vitta humerali a basi ultra medium extenso, flava ..." (MElzER, 1922).

Material-tipo. Melzer (1922) baseou a descrição da espécie em dois síntipos (MZSP) provenientes de São Paulo, sem indicar o sexo dos exemplares. Um síntipo (rotulado como "Typus") foi examinado por meio de diapositivo e tem a faixa sutural preta bastante larga. 
Distribuição. Até o momento, registrada apenas para o Brasil (Rio de Janeiro e São Paulo) (Monné, 2005).

Material examinado. BRASIL, Rio de Janeiro: Rio de Janeiro (Corcovado): \&, X.1958; ๘, XI.1967; \&, IX.1969, Alvarenga \& Seabra col.; §̋, X.1975, Monné \& Campos Seabra col. (MNRJ); 6 §, , , X.1968, Alvarenga col.; §', IX.1967, Alvarenga \& Seabra col.; †, IX.1956, ơ, X.1956, 2 ơ, IX.1958, Zajciw col.; ơ, X.1962, 4 శ, 4 \&, XII.1965, ơ, \&, X.1967, Moure \& Seabra col.; 2 శ, IX.1969, Alvarenga \& Seabra col. (DZUP).

\section{Eriphosoma marcela sp. nov. (Fig. 6)}

Macho. Tegumento preto, exceto protórax e mesosterno alaranjados; região circum-escutelar, em um exemplar, preto-alaranjada (Fig. 6).

Clípeo com pontos densos moderadamente grossos. Artículo apical dos palpos maxilares com a margem interna expandida da base até o meio, depois obliquamente truncada para o ápice que é brevemente truncado; dos labiais, fortemente expandido para o ápice.

Antenas ultrapassam o ápice elitral em três artículos. Escapo ligeiramente engrossado para o ápice, opaco, forte e densamente pontuado, os pontos até confluentes; pilosidade castanha muito esparsa. Antenômeros III-XI fina- e densamente pontuados, a pubescência progressivamente mais curta e densa para os distais; I-IV(V) com cerdas acastanhadas na face ventral, mais adensadas nos III-V; III-IV com espinho apical interno curto, o ápice externo inerme; III-V com carena dorso-lateral muito fina. Antenômero III cerca de um quarto mais longo que o IV, este pouco mais curto que o V; V-X pouco e gradualmente decrescentes; XI cerca de um quarto mais curto que o III.

Protórax quase tão longo quanto largo. Pronoto e lados do protórax com pontuação reticulada muito superficial, quase inaparente, e cerdas alaranjadas, curtas e esparsas, mais aparentes nos lados do protórax. Protórax e pronoto, a cada lado na metade anterior, com áreas de pontuação sexual ovaladas e deprimidas, com pontos grossos, irregulares e contíguos, fracamente microesculturadas, tornando essas áreas mais brilhantes do que o restante da superfície. Prosterno opaco, com pontos grossos e rasos, uniformemente distribuídos em toda a superfície; pubescência muito curta, quase inaparente. Mesosterno opaco, impontuado com pubescência esbranquiçada pouco aparente. Metasterno, metepisternos e urosternitos microcorrugados com pontos maiores e rasos, moderadamente densos e uniformemente distribuídos em toda a superfície; revestidos com pubescência esbranquiçada, com cerdas alongadas mais aparentes no disco dos urosternitos.

Escutelo opaco, glabro, sem pontos. Élitros ligeiramente adelgaçados na região mediana, a curvatura apical bem acentuada. Superfície fortemente opaca, com pontos grossos, densos e não-alinhados desde a base, tornando-se mais finos, densos e com aspecto biselado para os ápices; cerdas esbranquiçadas e eretas bem aparentes em toda a superfície. Espinho externo do entalhe látero-apical mais longo que o dente interno e que o espinho sutural.

Mesofêmures com pontos muito grossos, alongados, densos a confluentes e profundos até os ápices; os pontos com microscultura fraca, os interstícios brilhantes; cerdas castanho-amareladas esparsas. Metafêmures com escultura e pilosidade semelhantes, os pontos mais superficiais.

Dimensões, mm, ơ. Comprimento total 9,8-8,2; comprimento do protórax 1,9-1,6; largura do protórax 2,01,7; comprimento do élitro 7,2-6,0; largura umeral 2,4-2,0.

Material-tipo. Holótipo §’, BRASIL, Espírito Santo: Linhares (Parque Sooretama), 2.XI.1964, Werner, Oliveira \& Seabra col. (MNRJ). Parátipos, mesmos dados do holótipo: 2 ๑ (MNRJ, DZUP).

Discussão. Eriphosoma marcela sp. nov. assemelha-se a E. bipartitum (Buquet) pelo colorido alaranjado do protórax. Difere, inclusive dos exemplares de E. bipartitum com élitros negros e máculas pretas indistintas na base do pronoto, pelos antenômeros III-V carenados e os III-IV com espinho apical interno curto, mesofêmures com pontos alongados e muito grossos em toda a superfície, presença de áreas de pontuação sexual nos lados do pronoto e protórax nos machos e de pontos rasos, grossos uniformemente distribuídos no metasterno, metepisternos e urosternitos.

O epíteto é um nome aposto em homenagem à Dra. Marcela Monné (MNRJ) pela contribuição ao estudo dos Cerambycidae.

\section{Eriphosoma mermudes sp. nov.}

$$
\text { (Figs. 3, 5) }
$$

Macho. Tegumento inteiramente preto. Pronoto e grande área de aspecto triangular que abrange toda a região basal dos élitros e se estende em forma de faixa até o meio dos élitros, com aspecto aveludado (Fig. 3).

Genas pouco mais brilhantes que a fronte, com pontos adensados, subglabras, arredondadas no ápice, mais curtas que um terço da largura do lobo ocular inferior. Clípeo fortemente opaco, densa- e irregularmente pontuado. Artículo apical dos palpos maxilares e labiais dilatados para o ápice que é obliquamente truncado; o labial mais fortemente expandido e tão longo quanto os dois anteriores somados.

Antenas não-carenadas, ultrapassam o ápice elitral em dois artículos. Escapo densamente pontuadocorrugado, um pouco brilhante, com cerdas castanhas esparsas, mais longas na face inferior. Antenômeros IIIV finamente pontuado-corrugados, brilhantes, com pilosidade castanha deitada e longas cerdas castanhas na face inferior, mais abundantes nos III-IV; VI-XI finamente pubescentes; III-V com espinho apical interno curto. Antenômeros V-VII com comprimentos iguais, cerca de um terço mais curtos que o III; IV pouco mais curto que o V e tão longo quanto os VIII-IX; XI cerca de um terço mais curto que o III.

Protórax tão longo quanto largo. Pronoto e lados do protórax fina- e densamente reticulados, com aspecto aveludado e raríssimas cerdas muito curtas, quase inconspícuas. Protórax e pronoto, a cada lado na metade anterior, com áreas de pontuação sexual, ovaladas e deprimidas, com pontos grossos, irregulares e contíguos, 

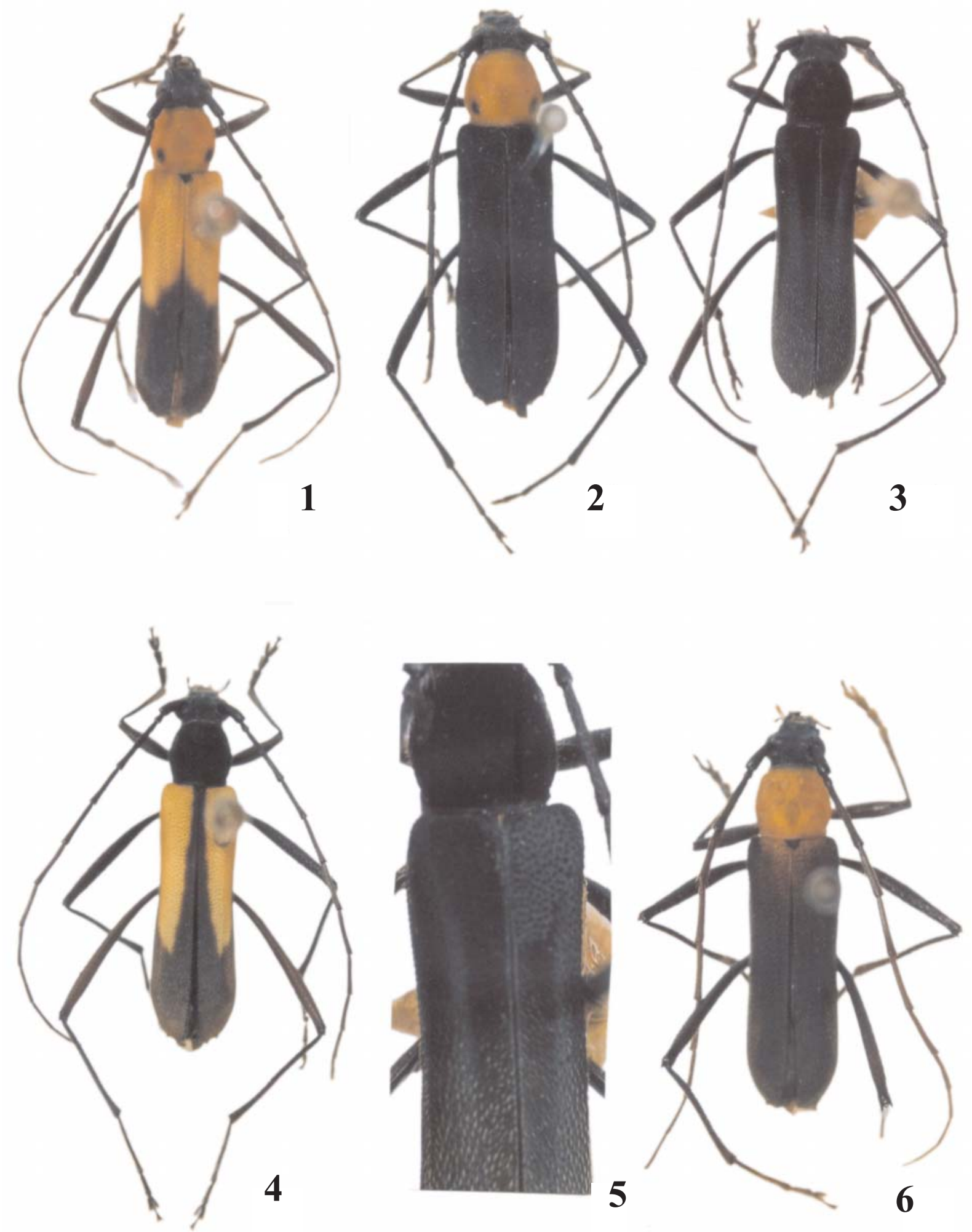

Figs. 1-6. 1, Eriphosoma bipartitum (Buquet), ơ do Rio de Janeiro (Corcovado), Rio de Janeiro, Brasil, comprimento 8,2 mm; 2 , Idem, \& de Loreto, Misiones, Argentina, comprimento 9,5 mm;3, E. mermudes sp. nov., holótipo o, comprimento 9,0 mm; 4, E. barbiellinii Melzer, $\sigma^{7}$ do Rio de Janeiro (Corcovado), Rio de Janeiro, comprimento $9,7 \mathrm{~mm}$; 5, E. mermudes sp. nov., parátipo $\sigma^{\prime}$, detalhe dos élitros; 6, E. marcela sp. nov., holótipo ơ, comprimento $9,8 \mathrm{~mm}$. 
sem aspecto aveludado. Mesosterno, metasterno e urosternitos fina- e densamente corrugados, com pubescência esbranquiçada e cerdas longas, esbranquiçadas, esparsas em toda a superfície.

Elitros um pouco adelgaçados no terço mediano, a curvatura apical bem acentuada. Região basal (Fig. 5) com pontos grossos, densos a corrugados, especialmente na região circum-escutelar; restante da superfície opaca, com pontos não-alinhados, progressivamente mais finos para os ápices, e cerdas esbranquiçadas bem aparentes. Ângulos do entalhe látero-apical igualmente projetados; ângulo sutural com espinho curto e delgado.

Mesofêmures grossa-, profunda- e densamente pontuados, os pontos conspicuamente menores e mais densos no quarto apical. Metafêmures brilhantes, com pontos biselados, superficiais e moderadamente densos.

Fêmea. Antenas tão longas ou pouco mais curtas que o corpo. Protórax sem pontuação sexual. Metafêmures não atingem o ápice elitral. Artículo apical dos palpos maxilares menos dilatados do que os do macho.

Dimensões, em mm, $\sigma / \$$ respectivamente. Comprimento total 9,0-8,5/10,0-9,0; comprimento do protórax 1,7-1,5/1,7-1,6; largura do protórax 1,7-1,5/2,01,7 ; comprimento do élitro 6,8-6,4/7,7-6,7; largura umeral 2,2-1,9/2,5-2,0.

Material-tipo. Holótipo ơ, BRASIL, Bahia: Encruzilhada (Motel da Divisa, Estrada Rio-Bahia km 965, 960 m), XII.1974, Seabra \& Roppa col. (MNRJ). Parátipos: mesma procedência do holótipo, \&, X.1971, Seabra \& Roppa col. (MNRJ); \&, XI.1974, o', XII.1974, Seabra \& Roppa col. (DZUP). Minas Gerais: Águas Vermelhas, 2 \&, XI.1970, F.M. Oliveira col. (MNRJ).

Discussão. E. mermudes sp. nov. distingue-se das demais espécies do gênero pela combinação dos seguintes caracteres: colorido inteiramente preto; região basal dos élitros com grande área aveludada de aspecto triangular que se estende em forma de faixa aos lados da sutura até o meio dos élitros; pontuação na base dos élitros muito densa a corrugada.

Eriphosoma marcela sp. nov. e formas melânicas de E. bipartitum (Buquet) também apresentam élitros negros. A nova espécie difere de E. marcela, além dos caracteres mencionados acima, pelo colorido negro do protórax e mesosterno, antenas não-carenadas, pontuação dos metafêmures e ausência de pontos grossos no metasterno e urosternitos. De E. bipartitum, difere pelo protórax negro, antenômeros III-V com espinho apical interno, pontuação da base dos élitros muito densa a corrugada e presença de áreas de pontuação sexual nos lados do pronoto e protórax nos machos.

O nome da espécie, aposto, homenageia o Dr. José Ricardo M. Mermudes (MZSP) por sua contribuição ao estudo de Coleoptera, famílias Cerambycidae e Anthribidae.

\section{Eriphosoma jacobi Fuchs, 1961 (Figs. 7, 8)}

Eriphosoma jacobi Fuchs, 1961:17; MonnÉ, 2005:289.
Não examinada. A redescrição apresentada a seguir baseia-se nas fotos do holótipo e de um parátipo, gentilmente enviadas por Herbert Schmidt (Viena), e na descrição original. Fuchs (1961) não menciona o sexo dos exemplares estudados e, pelas fotos, não foi possível chegar a uma definição.

Tegumento preto. Élitros vermelhos ou amarelados com o quinto apical preto (Figs. 7,8).

Cabeça densamente reticulada. Fronte quadrangular, fina- e densamente pontuada, com um pequeno triângulo liso antes da margem anterior. Vértice grossa- e densamente pontuado. Olhos profundamente emarginados, finamente facetados; lobos superiores distantes entre si, os inferiores tão longos quanto as genas. Tubérculos anteníferos aplanados. Artículo apical dos palpos maxilares fortemente expandido para o ápice.

Antenas ultrapassam o ápice elitral em dois artículos, os antenômeros I-VI com cerdas na face inferior. Escapo forte e densamente pontuado. Antenômero III o mais longo, quase duas vezes tão longo quanto o escapo e o antenômero IV, que é mais curto que os seguintes; V$\mathrm{X}$ subiguais, decrescentes e um pouco angulosos; XI cerca de um terço mais curto que o III. Antenômeros III$\mathrm{V}$ com espinho curto no ápice interno.

Protórax arredondado nos lados, reticulado. Processo prosternal estreito, o mesosternal largo, plano, emarginado no ápice. Metepisternos estreitos e paralelos. Face ventral do corpo muito densa- e finamente pontuada.

Escutelo densamente pontuado. Élitros paralelos, estreitos e alongados, bem atenuados no ápice. Com pontos mais ou menos alinhados, mais grossos e marcados na base, nos $2 / 3$ basais tão ou mais distantes entre si que o diâmetro de um ponto; no quarto apical, pontos mais finos e densos; cerdas curtas, alaranjadas, bem aparentes em toda a superfície. Ápices entalhados no lado externo com espinho externo curto, mais projetado que o mediano e o sutural.

Fêmures delgados com abas apicais aguçadas. Mesofêmures grossa-, profunda- e densamente pontuados, com pilosidade esparsa. Metafêmures ultrapassam o ápice elitral. Metatíbias cilíndricodeprimidas. Metatarsômero I mais longo que os demais somados.

Material-tipo. Holótipo (Fig. 7) do PARAGUAI, Itapúa: Hohenau (Alto Paraná), Jacob col. (CHSV, ex-Coleção Fuchs). Parátipos: BRASIL, Santa Catarina: Nova Teutônia (atualmente Município de Seara), Plaumann col., 1 exemplar na CHSV (exColeção Fuchs) (Fig. 8), e outro no Museu Entomológico Fritz Plaumann (Brasil, Santa Catarina, Seara).

Discussão. Por não ter sido examinada, E. jacobi é mantida, provisoriamente, como espécie válida em Eriphosoma. Fuchs (1961:18), menciona que em um dos parátipos de Nova Teutônia os élitros são amarelados e fracamente entalhados no lado externo dos ápices (Fig. 8), o que levou MonNé (2005) a registrar apenas a localidade-tipo. Pelo exame das fotos do holótipo e do parátipo, parece provável que o exemplar de Nova Teutônia seja co-específico e o registro da espécie para Santa Catarina, Brasil é, por enquanto, mantido. Com relação às antenas, Fuchs (1961) não menciona a presença 


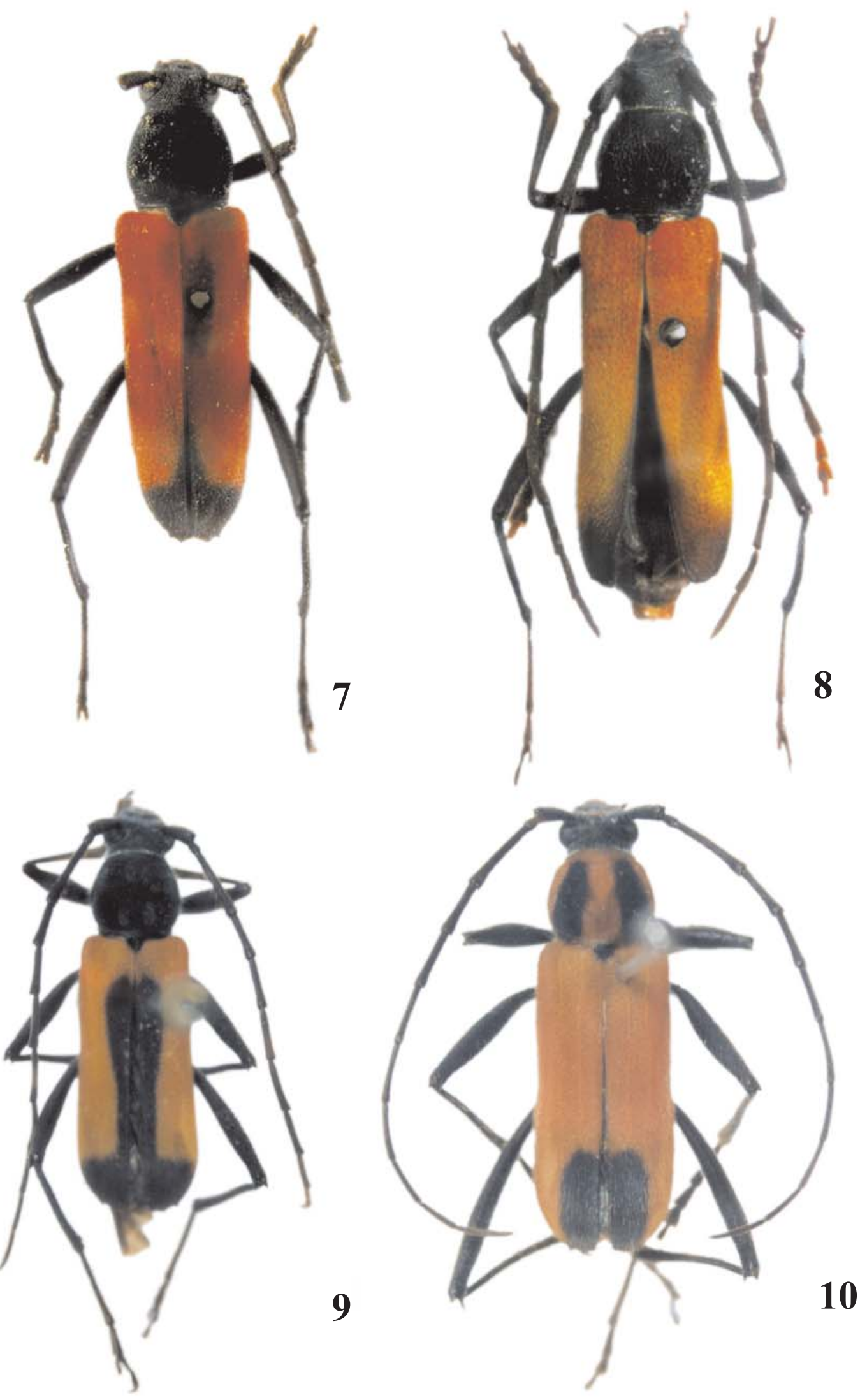

Figs. 7 - 10. 7, Eriphosoma jacobi Fuchs, holótipo; 8, Idem, parátipo; 9, Erythrochiton sellatum (Buquet), $\sigma$ do Rio de Janeiro (Corcovado), Rio de Janeiro, comprimento $8,9 \mathrm{~mm}$; 10, E. nigrosignatum Zajciw, parátipo $\widetilde{\jmath}$, ibidem, comprimento 10,0 mm. 
de espinhos no ápice interno dos antenômeros III-IV, o que pode ser observado nas fotos dos tipos.

Eriphosoma jacobi assemelha-se a E. barbiellinii Melzer, pelo protórax preto e élitros bicolores. As duas espécies distinguem-se pelos caracteres mencionados na chave.

\section{Erythrochiton sellatum (Buquet, 1844) comb. nov. (Fig. 9)}

Eriphus sellatus Buquet in GuÉRIN-MÉneVILle, 1844:226.

Eriphosoma sellatum; Melzer, 1922:10; MonNÉ, 2005:289.

Eriphus sellatus Buquet, 1844 deve ser transferida para o gênero Erythrochiton Zajciw, 1957 por apresentar: fronte quadrangular, genas quase tão longas quanto a largura dos lobos oculares inferiores; olhos com chanfro acentuado, afastado da margem dos tubérculos anteníferos; lobos oculares inferiores moderadamente desenvolvidos, não-proeminentes e restritos aos lados da cabeça; élitros proporcionalmente mais curtos e largos, com comprimento cerca de 2,5 vezes a largura umeral, os úmeros não-projetados para frente; fêmures robustos e proporcionalmente mais curtos.

Em Erythrochiton, E. sellatum (Buquet) (Fig. 9) é semelhante a E. nigrosignatum Zajciw, 1957 (espécietipo), distinguindo-se por: (1) protórax preto; (2) élitros com faixa sutural negra e larga que se inicia logo após o escutelo e se estreita para trás, atingindo, ou não, a mácula preta apical; (3) antenômeros III-V carenados; (4) abas apicais dos metafêmures pouco projetadas e subiguais; (5) metafêmures ultrapassam o ápice elitral pela extremidade dos fêmures. Em E. nigrosignatum (Fig. 10), o protórax é vermelho com duas áreas pretas, alongadas nos lados do pronoto; os élitros são destituídos de faixa sutural preta; os antenômeros III-V não são carenados; os metafêmures têm abas apicais projetadas, a interna mais longa que a externa, e ultrapassam o ápice elitral em cerca de um quarto de seu comprimento.

Material-tipo. De Eriphus sellatus Buquet, 1844: nãoexaminado. Espécie descrita com base em único exemplar proveniente "du Brésil" e depositado no MNHN. De Erythrochiton nigrosignatum Zajciw, 1957 foram examinados holótipo o

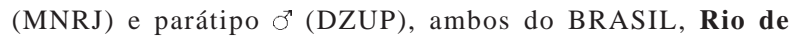
Janeiro: Rio de Janeiro (Corcovado), I.XI.1955 e 28.X.1954, respectivamente, D. Zajciw col.

Distribuição. MonNÉ (2005) registra E. sellatum para o Brasil (Minas Gerais ao Rio Grande do Sul), Paraguai e Argentina, e E. nigrosignatum apenas para o Brasil (Espírito Santo e Rio de Janeiro).

Material examinado. De E. sellatum: BRASIL, Espírito Santo: Conceição da Barra, F, IX.1968, C.T. \& C. Elias col. (DZUP); Santa Tereza, \&, X.1964, C. Elias col., 3 \&, XI.1964, C. \& C.T. Elias col. (DZUP). Rio de Janeiro: Rio de Janeiro (Corcovado), \&, X.1957, ॐ, \&, XI.1958, D. Zajciw col.; 2 ॐ, , IX.1961, Moure, Alvarenga \& Seabra col.; †, X.1961, đ’, XI.1961, Seabra \& Alvarenga col.; \&, X.1962, Alvarenga \& Seabra col.; 2 §., \&, XII.1965, 2 \%, \&, XII.1966, Moure \& Seabra col.; 2 , X.1968, Alvarenga col. (DZUP).

De E. nigrosignatum: BRASIL, Espírito Santo: Conceição da Barra, 2 ơ, , 1-7.X.1968, C. \& C.T. Elias col. (DZUP). Rio de Janeiro: Rio de Janeiro (Corcovado), $\vec{\sigma}$, 16.X.1954, Zajciw col. (DZUP).

Agradecimentos. A Herbert Schmidt (CHSV), pelo envio das fotos do holótipo e parátipo de Eriphosoma jacobi, e a Albino M. Sakakibara (DZUP) pelas demais fotos que ilustram o trabalho.

\section{REFERÊNCIAS BIBLIOGRÁFICAS}

Buquet, J. B. L. 1844. In: Guérin-Méneville, F. E. Iconographie du règne animal de $\mathbf{G}$. Cuvier, Insectes. Paris, Baillière. v. 7, p.5-576.

Fuchs, E. 1961. 4. Beitrag zur Kenntnis der neotropischen Cerambyciden. Koleopterologische Rundschau 39:6-21.

Melzer, J. 1922. Longicórneos (Col.) do Brasil, novos ou pouco conhecidos. Notas Preliminares do Museu Paulista 2(2): 1-12.

Monné, M. A. 1994. Catalogue of the Cerambycidae (Coleoptera) of the Western Hemisphere. Part X. São Paulo, Sociedade Brasileira de Entomologia. 81p.

2005. Catalogue of the Cerambycidae (Coleoptera) of the Neotropical Region. Part I. Subfamily Cerambycinae. Zootaxa 946: $1-765$.

Napp, D. S. \& Monné, M. A. 2005. Synopsis of the genus Erythropterus Melzer, 1934 (Coleoptera, Cerambycidae, Heteropsini). Zootaxa 1088:55-59.

ZaJciw, D. 1962. Estudos sôbre longicórneos neotrópicos III (Coleoptera, Cerambycidae). Revista Brasileira de Biologia 22(4):449-452.

Recebido em novembro de 2005. Aceito em janeiro de 2006. ISSN 0073-4721

Artigo disponível em: www.scielo.br/isz 